\title{
The Effect of Heat Treatment on Corrosion Resistance of 6061 Aluminum Alloy
}

\author{
Chuan-bo Zheng ${ }^{1}, \mathrm{Xi}$ Chen ${ }^{1}$, Chun-ling Li ${ }^{1}$, Xiao-lan Shen ${ }^{1}$, Ke Cheng ${ }^{2,3}$ \\ ${ }^{1}$ Jiangsu University of Science and Technology, Materials Science and Engineering, Zhenjiang \\ 212003, China; \\ ${ }^{2}$ School of Computer Science and Engineering, Jiangsu University of Science and Technology, \\ Zhenjiang Jiangsu 212003, China \\ ${ }^{3}$ Key Laboratory of Modern Agricultural Equipment and Technology, Ministry of Education and \\ Jiangsu Province, Jiangsu University, Zhenjiang Jiangsu 212013, China \\ *E-mail: 70533316@qq.com
}

doi: $10.20964 / 2016.08 .35$

Received: 23 March 2016 / Accepted: 21 May 2016 / Published: 7 July 2016

In this paper, the corrosion resistance in $3.5 \% \mathrm{NaCl}$ solution of 6061 aluminum alloys after different heat treatment is investigated by slow strain rate equipment, polarization curves and impedance, combining scanning electron microscopy. The results showed that the results of three methods are consistent. The tensile fracture time of the alloy after solution treatment is longest, the one of alloy after dual-stage aging is shorter, and the one of alloy after single-stage aging is shortest; the passivation film of alloy after solution treatment is most stable, with the largest value of impedance, the passivation film of dual-stage aged and single-stage aged alloys are poorly stable, the impedance values are lower. Dual-stage aging makes the second phases coarser, cutting off continuous anodic dissolution channel and owing a smaller current density than single-stage aging alloys.

Keywords: 6061 aluminum alloy; heat treatment; slow strain rate; polarization curves; impedance

\section{FULL TEXT}

(C) 2016 The Authors. Published by ESG (www.electrochemsci.org). This article is an open access article distributed under the terms and conditions of the Creative Commons Attribution license (http://creativecommons.org/licenses/by/4.0/). 